\title{
Interreligious Dialogue in the Governance of Migration and Interethnic Cohabitation
}

\author{
Fabio Baggio
}

Without the acknowledgement of his spiritual being, without openness to the transcendent, the human person withdraws within himself, fails to find answers to the heart's deepest questions about life's meaning, fails to appropriate lasting ethical values and principles, and fails even to experience authentic freedom and to build a just society (Benedict XVI, 2010).

The words of Pope Benedict XVI are a perfect incipit for this chapter, with which we propose to highlight the importance of interreligious dialogue in the governance of contemporary migration flows and multi-ethnic cohabitation.

According to data gathered by the Pew Research Center, in 2010, 83.7\% of the global population said they adhered to a religion (Pew Research Center, 2012a). Based on this statistic alone, it is evident how the religious dimension represents an important aspect in the life of the great majority of people. Consequently, every act of government that wants to be oriented to the good of people cannot be exempted from this essential consideration. Also, the governance of migration flows and multi-ethnic cohabitation, as a political exercise, must include the religious dimension among the areas of greatest interest, promoting interreligious dialogue.

Before moving to the real discussion, we think it is appropriate to present some methodological clarifications. A large part of the considerations expressed further below are the fruit of a personal reflection based on first hand experiences in different regions of the world. The spiritual dimension discussed in this article is, by its very nature, difficult to measure in scientific terms: this represents at the same time a challenge and a limit of my study. Considering my Catholic faith, we will make frequent reference to the teaching of the Church, particularly its universal teaching, without failing to mention thought developed in other religious contexts. 


\section{The Essentiality of the Religious Dimension}

At the historical level, it is undeniable the role that religions -and the values proclaimed by them-have had in the construction of the different civilizations which have marked the continuous progress of humanity in the various regions of the world. The opening to the transcendent, considered in its multiple forms, has profoundly characterized human evolution in ages and places that are so different that it is hard to believe it is not primarily constitutive to the human being. Its dogmatic and cultural structuring and its different institutionalizations, while developing over time, have resisted attacks of all kinds, often becoming a reason for resilience and survival. There are also considerable and widely documented contributions from the various religions in the moral, political, cultural and artistic spheres in all regions of the world. And in addition to what is expressed above, it cannot be denied that a large part of humanity adheres to a religion and that, again according to the Pew Research Center, a significant percentage of people who say they are not part of any religion in fact also confess to having some religious belief (Pew Research Center, 2012a).

What has been presented above should be sufficient to demonstrate how religiosity -or spirituality- makes up a substantial dimension of human realization that cannot be omitted in any debate that regards the human according to Terence (Heautontimorumenos, I, 1, 25). In other words, promoting the realization of this dimension of human existence contributes to the full realization of the human being. As Pope Benedict XVI affirmed, "The religious dimension is in fact intrinsic to culture. It contributes to the overall formation of the person and makes it possible to transform knowledge into wisdom of life" (Benedict XVI, 2009). The pope explains a conviction of Christian doctrine that is rooted in the Jewish tradition, which considers the denial of the existence of God as foolishness, with ominous consequences in moral life: "The fool says in his heart, "There is no God". They are corrupt, they do abominable deeds, there is none that does good" (Psalm 14:1.). According to Islam, the human being has two series of essential needs: spiritual and material. The first are satisfied through faith in Allah; the second by using the resources that Allah has created for that purpose in the best way (Ahmad Kausar et al., 2013). Regarding the Hindu, Jainist and Buddhist traditions, human realization consists in the capacity to elevate oneself from the material sphere to the spiritual sphere, through a process of personal purification.

In the contemporary age, two trends have affirmed themselves that have contributed to challenging the essentiality of the religious dimension in human realization: the acclamation of the superiority of secularism and the political-ideological abuse of religion. 
It is evident how in some environments a hostile attitude toward religions has spread widely, with religions standing accused of conditioning and interference in the management of the res publica. Starting from the principle that religiosity belongs to the private sphere and has to be kept that way in every political exercise, many moral values, which find their reason for being in religious traditions, have been banned from public debate. In the name of a supposed superiority of being a-religious in the secular sphere, political discourse has disappeared, eliminating any reference to spirituality and transcendence, leading to the view that religious affiliation in fact makes up an impediment to the good exercise of government, and that beliefs are irrational, fruit of superstition and anti-modern. All of this has contributed to increasing disaffection toward the traditional religions, which have already been tested by processes of secularization. Deprived of its collective and moral value, religion has ended up among the "optional" aspects of human realization: an elective -and private- hour in the calendar of life.

Regarding this, in 2005, Pope John Paul II warned on the threats of secularism to religious freedom:

A mind-set inspired by a secular outlook is spreading in society. This ideology leads gradually, more or less consciously, to the restriction of religious freedom to the point that it advocates contempt for, or ignorance of, the religious environment, relegating faith to the private sphere and opposing its public expression. (...) A correct concept of religious freedom is incompatible with this ideology that is sometimes presented as the only rational voice. Religious freedom cannot be curtailed without depriving human beings of something fundamental. (John Paul II, 2005)

The second trend, which is just as widespread currently, is the exploitation of religion for ideological and political aims. Even if history is rich in episodes of this kind, it was thought that this sort of "abuse" could not "take root" in contemporary societies. Unfortunately, the news reveals the opposite, as the Parliament of the World's Religions underlined some years ago: "Time and again we see leaders and members of religions incite aggression, fanaticism, hate, and xenophobia - even inspire and legitimize violent and bloody conflicts. Religion often is misused for purely power-political goals, including war" (Parliament of the World's Religions, 1993).

Abused for personal interests, retaliation or revenge, religions are used to mark out differences, counterpose civilizations, oppress the most vulnerable, and justify wars. But "wars of religions" often become "wars against religion" 
due to the fact that they contribute to perverting the nature of religious affiliation, depriving it of its aspect of being transcendent, mystic and an instigator of good.

Faced with these challenges, the necessity arises to re-establish the essential role that corresponds to the religious dimension, restoring the inspiring principles of religions and reinstating the great ideals of truth, justice and solidarity. The necessary first step is the recognition of religious freedom. In 2001, John Paul II wrote:

Basic to all human rights is the freedom of religion, which includes the right to be instructed in the faith. (...) This requires that governments and school authorities ensure that this right is effectively respected. (...) Men and women religious, lay people and clergy have labored to achieve this end, often with prodigious effort and many sacrifices. Their work needs to be consolidated and extended to ensure that all the baptized grow in faith and in understanding of the truth of Christ. (John Paul II, 2001: 22)

As a corollary to the recognition of freedom of religion, with a view to a peaceful and enriching cohabitation in multi-cultural societies, John Paul II (2001) encourages all stakeholders to commit themselves to an ecumenical and interreligious dialogue, seeking to avoid any type of fundamentalism.

\section{The Religious Dimension in the Migration Process}

As it is logical to suppose, migrants are worthy representatives of the people of their countries at the religious level. Their religious affiliation generally corresponds to the percentages observed in their homeland. With regard to international migrants, some estimates already exist that we find useful to consider when examining this point.

According to data gathered by the already-cited Pew Research Center (2012b), in 2010, of the 210 million international migrants estimated by the United Nations, 106 million were Christians (49\%), 60 million were Muslims (27\%). The rest were made up of Hindus ( $5 \%)$ Buddhists $(3 \%)$, Jews $(2 \%)$, other religions $(4 \%)$ and unaffiliated believers and non-believers $(9 \%)$.

In the 27 countries of the European Union, again according to data elaborated by the Pew Research Center, in 2010, the religious composition of migrants who were citizens of non-member countries was the following: $42 \%$ Christians, $39 \%$ Muslims, $8 \%$ unaffiliated or atheists, $3 \%$ Buddhists, $2 \%$ Hindus, $1 \%$ Jewish and $4 \%$ of other religions. 


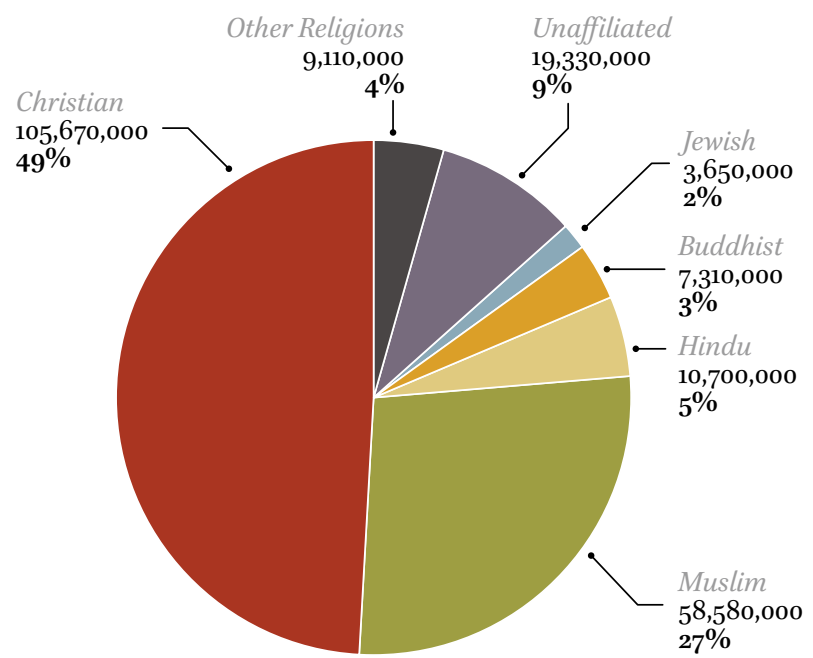

FIGURE 15.1 Religious composition of international migrants, 2010 SOURCE: PEW RESEARCH CENTER, 2012B: 11

These numbers, however, only give an idea of the importance of religiosity for migrants, which very frequently is not limited to a mere declaration of affiliation. The religious dimension, in its symbolic and cultural expressions, is essential for many migrants in the various phases of the migration process: departure, journey and arrival/residence.

In recent decades, scientific production on this theme has been enriched thanks to contributions from anthropologists, sociologists, theologians and religion experts, who have formulated interesting theories, often starting from the observation of specific cases. These theories can be classified in three big groups based on their main subject: those that regard personal faith as a spiritual and social resource for migrants, those that refer to the role of religious communities for immigrants, and those that concentrate on transnational dynamics of migrants in the religious sphere (Frederiks, 2016).

In the large part of cases, the analysis of researchers has focused on immigrant communities. Some studies have gone into depth also on other phases of the migration process. This is the case of J. Hagan and H.R. Ebaugh, who studied the role of religion in the whole migration process of the Maya population of San Pedro, Guatemala, to Houston, Texas. The people who intend to depart usually turn to ministers of the Pentecostal Church to obtain advice in their decision process. The same people participate in large numbers in moments of fasting and prayer (ayunos) in which qualified pastors prophesize, indicating God's will for each person. Once the decision is made, the migrants, along with 

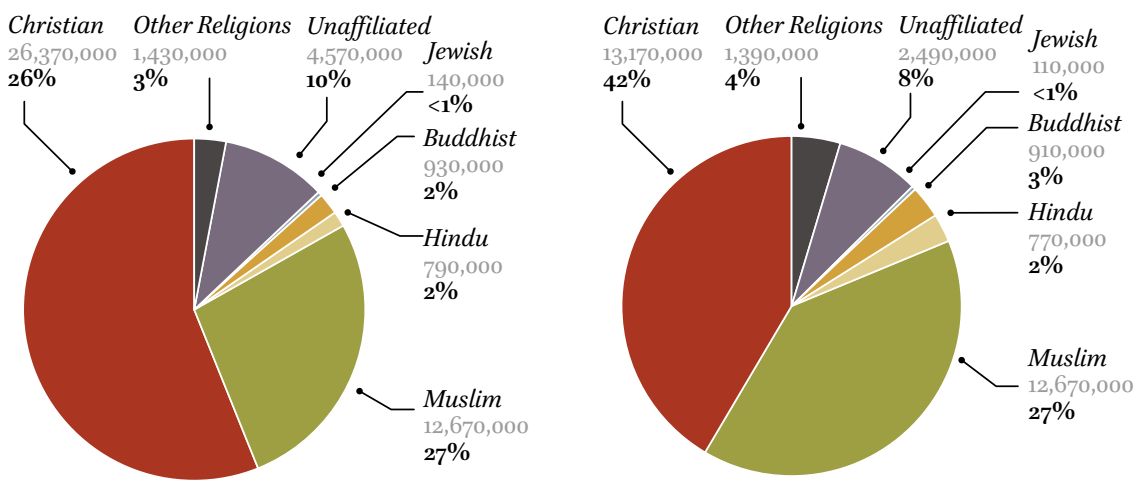

FIGURE 15.2 Religious composition of international migrants in the EU, 2010 SOURCE: PEW RESEARCH CENTER, 2012: 54

their families, refer to the ministers again for the necessary preparations. Often, the ministers are requested to check the honesty of the guides (coyotes) who lead the migrants in the long and dangerous journey (Hagan, Ebaugh, 2003). Again J. Hagan, this time along with H. Straut Eppsteiner, underlines how particularly in the cases in which the migration is ventured through irregular channels, and for this reason, is set to be risky, the departing -often with their relatives- turn to divinities to obtain strength and protection. This is the case for many Catholics in Guatemala and Mexico who make pilgrimages to sanctuaries, carry out devotional practices and offer ex voto objects in exchange for "spiritual travel permits" (Straut Eppsteiner, Hagan, 2016). Already in 1980, P.A. McAllister explained how the Gkaleca, an indigenous group of South Africa, practiced special propitiatory rites before the departure of migrant workers, with the aim of obtaining protection and guarantee of return from the spirits (McAllister, 1980).

During the second phase of the migration process, or the journey, religion continues to be important for many people on the move. In a study published by L.J. Dorais in 2007, the interviews with Vietnamese refugees of different religions (Buddhists, Catholics and Caodaists) revealed how each person had found comfort, hope, consolation and strength of spirit in prayer and in religious practices (Dorais, 2007). From the testimonies that I could gather personally, I was able to glimpse the same faithful abandonment and confident recourse in many migrants and refugees who braved the Sahara Desert and the waves of the Mediterranean Sea. After the adventurous crossing of the Mediterranean, for many migrants the path continued toward the North, and with it the trust in the transcendent, which was also manifested in the construction of real places of worship. This is how it was for Orthodox Christian and Muslim 
migrants in the so-called "jungle" of Calais, who wanted to entrust their dreams to divine providence in a church and a mosque built with their own hands ("Corriere della Sera", 9 August 2015). These are the same convictions that lead many Central American migrants to build sanctuaries along the "vertical border" that is Mexico, to jealously guard pictures of the saint they have entrusted themselves to in their pockets, to wear miraculous medallions around their neck and to sculpt sacred images in stones along the way (Straut Eppsteiner, Hagan, 2016).

The importance of the dimension in the third migration phase, made up of the arrival and residence in the country of destination, is surely that which has been the most common subject of studies in recent decades. In the case of Maya migrants in the United States, studied by Hagan and Ebaugh, communication with relatives who remained in the homeland is kept alive also thanks to religion. The migrants send photos to families in Guatemala so that they can be taken to the ayunos. The pastors commonly show hundreds of photographs to indicate that the propitiatory rites had their effect. On the other side, the pastors of the "sister" Churches in the United States hang photographs on the walls of reunited relatives who were prayed for, in this way closing a spiritual circle of divine protection. Furthermore, the Pentecostal communities in US cities offer immediate social support networks for the new arrivals and contribute to maintaining the feeling and the religious practices of the country of origin among immigrants (Hagan, Ebaugh, 2003). Proof of the importance of the religious dimension in the migrant settlement process is provided by the intensification of the religious practice openly declared on the part of some ethnic groups, like in the case of Indians of the Hindu religion in the US interviewed by P. Kurien, many of these said they had rediscovered their religiosity in the land of emigration, also introducing expressions of regular collective worship which in their homeland were relegated to a few big celebrations $\mathrm{Ku}$ rien, 2002). Moreover, contemporary history is rich in similar examples; you only have to think of the religious vitality of the Italian Catholic immigrants in Argentina between 1800 and 1900 (Baggio, 2000), the robust community structuring of Hindus from Surinam in the Netherlands between 1970 and 1990 (van der Burgin, 1991), the cultural and institutional development of Muslim immigrants in Germany in the last 50 years (Troll, 2003), and the extraordinary adherence to evangelical Christian communities on the part of Korean and Chinese immigrants in the United States in the third millennium (Ambrosini, 2007).

It should also be noted how, in the residence phase, the religious practice of migrants usually produces a significant impact also on the religiosity of host societies, as shown by several pieces of research on the subject. R. Henkel and 
H. Knippenberg sustain that, thanks to the religiosity of immigrants, in Europe there has been a slowing in the process of secularization and religion has regained a space in the public sphere (Henkel, Knippenberg, 2005). In certain geographical areas, some religious confessions are today present only thanks to the mass arrival of immigrants, who have caused profound change in the religious landscape of some countries. This is the case of Christianity in the Gulf countries, brought by Philippine immigrants and Indians from Kerala. This is the case also for Hinduism in Britain and Canada (Frederiks, 2016). The most recent flows of Christian immigrants into the United States brought with them a new way of living and celebrating faith, which is obliging local communities to invent, along with the latest arrivals, new forms of praying, announcing and serving (Levitt, 2007).

\section{Religions in Dialogue}

The big religions, even in their diversity, offer a priceless common heritage of principles and values if meeting and dialogue is encouraged between them. As the Parliament of the World's Religions, underlines: "A common set of core values is found in the teachings of the religions, and (...) these form the basis of a global ethic" (Parliament of the World's Religions, 1993).

Some scholars say that the definition of a universally accepted ethical platform should be free from any religious consideration. Only a neutral -or rather purely philosophical- series of principles could overcome the divisions that exist between various faiths and beliefs (Nielsen, 1990). The development of this thought has led to three different philosophical orientations: the modern doctrine of natural law, ${ }^{1}$ normative hedonism ${ }^{2}$ and moral contractualism. ${ }^{3}$ The French philosopher Jacques Maritain was strongly opposed to the total secularization of ethics, advancing the theory of integral humanism. This theory

1 "A philosophical-juridical current founded on two principles: the existence of natural law (corresponding, that is, to the nature of man and therefore intrinsically right) and its superiority over positive law". "Giusnaturalismo", Treccani - Enciclopedia On Line, http://www.treccani.it/enciclopedia/giusnaturalismo/ (accessed October 5, 2018).

2 Normative hedonism says that pleasure is a value and suffering is a disvalue regardless of the value of anything they can cause or prevent. See. "Hedonism", Stanford Encyclopedia of Philosophy, http://plato.stanford.edu/entries/hedonism/ (accessed October 5, 2005).

3 Moral contractualism defines as right the action that can be rationally justified by the individual and approved on the part of other members of the social group of reference. See P. Marrone, "Contrattualismo morale e intellettualismo etico in T. Scanlon", Etica \& Politica / Ethics \& Politics, 2, 2010, 2, 369-370. 
founds itself on the conviction that the human person is at the same time material and spiritual and for this reason the religious dimension, understood beyond any confessional sense, cannot be excluded from ethical debate (Maritain, 1996). And it is worth adding that, considering the large part of humanity defines itself as religious, it would be unreasonable to exclude the spiritual dimension from the start from the determination of the ethicality of human behavior.

In the world of today, strongly marked by questionable truths and random interpretations, an inclusive approach could better respond to contemporary ethical challenges. This does not therefore involve the search for universality of principles "beyond" religions, but "together" with them, to reach the point of being able to define the rules of a common wisdom, which integrates the moral paradigms of the different philosophies and faiths. For this reason, in the ethical debate -and at the same time in every public debate- no one should renounce one's own religiosity (Carter, 1993).

Some attempts in this direction are worthy of mention. In the 1990s, a process of interreligious reflection resulted in the document The Declaration Toward a Global Ethic that was adopted by the Parliament of the World's Religions in 1993. The global ethics proposed in the declaration are founded on common values advocated by the different religions that took part in the process. More recent is the proposal by Darrell Fasching and Dell Dechant, who suggest a comparative narrative approach to the different religious ethics, of which the result is structured in a normative ethics of human dignity and liberation, in conformity with the Universal Declaration of Human Rights (Fasching, Dechant, 2001). A third attempt, named "ethics through cultures" proposes a purely descriptive approach to morality, with great consideration for cultural and religious differences, without any kind of judgement (Brannigan, 1998; Guptara, 1998). Even in their diversity, these efforts made toward the definition of a universally accepted ethical paradigm coincide in the need to make different cultures and religions converse to obtain a result that is globally significant.

In the last few years, I have dedicated myself to going into more depth on this issue, making use of the study and meeting opportunities that my missionary experience has offered me. I managed to highlight some principles that the big religious and philosophical traditions concur on. The first of these refers to the existence of principles beyond human contingency. For many religious traditions, these are fruit of a divine revelation and respond to the will of a superior and transcendent being. For other traditions, these principles are registered in the cosmic order and can be understood through a process of enlightenment and purification. For many philosophical traditions, universal 
values exist that can be understood by all human beings beyond their spatialtemporal condition (Baggio, 2007).

A second principle that many religious and philosophical traditions have in common is that of the primacy of the common good over that of the individual. As the Lucca-based Group of the Ecclesial Movement for Cultural Commitment (MEIC) underlined in 2008:

In fact, all religions, through varied means, spur their own faithful to collaborate where they live, with all those who make efforts to ensure respect for the dignity of the human person and of their fundamental rights, to develop the sense of fraternity and of solidarity, to be inspired by the savoir faire of the community of believers that, at least once a week, bring together millions of people, of the utmost differences, in an authentic spiritual communion, and to help the men and women of this time to not be slaves of fashions, consumerism and profit. The believers are therefore called upon to contribute concretely to the common good, to an authentic solidarity, to the overcoming of crises, and to intercultural dialogue: they have to participate in public dialogue in societies they are members of. (MEIC, 2008: 38)

The coincidence with the big philosophical traditions of the East and West made itself evident in firstly the drawing up and then the application of the international conventions that protect human rights and promote their dignity.

The third principle of universal destination of goods on the earth, the first foundation of the "duty" of solidarity, finds the different religions and philosophical ethics in the world in agreement. The concept of a common wealth to share, overcoming historical divisions, can be justified by an explicit will of the divine creator or by respect for a cosmic order, which guides human history. Following on is a moral obligation of charity and sharing which in all cases responds to the full realization of one's own humanity according to a superior design. In an immanent philosophical perspective, many currents of thought consider philanthropy and solidarity as excellent virtues, even if these do not always reach the point of constituting a moral obligation for individuals (Baggio, 2014). It should anyhow be noted that, also in the secular sphere, there is no lack of people who advocate for the equal allocation of common resources as a duty for all, based on the principles of equality, non-discrimination and equal access to development (Atuguba, 2013).

A fourth principle is codified in the duty of hospitality toward the other, the stranger or in any case the person who does not belong to the group of 
reference. The major religious traditions coincide in situating that obligation in the sphere of the sacred; some justify it with the fact that the guest is specially protected by divinity due to their vulnerability; others base it on the mysterious presence of God himself in the guest; others furthermore see a way toward ascension and purification in the practice of unselfish hospitality (Baggio, 2007). In secular ethics, the offer of hospitality is generally a sign of civility, a demonstration of magnanimity, even if it does not reach the point of constituting a moral imperative. Cases exist, however, in which humanely reception cannot be denied. This is the case of those who escape war and persecution, for whom the duty of hospitality is set forth by international and national law (Gil-Bazo, 2015; see also Chapter 4).

Many religious traditions affirm the principle of the global management of the earth, from which springs a common duty to the whole of humankind around the correct administration, the healthy use and the harmonious development of environmental and natural resources. Some of these, such as Judaism, Christianity and Islam, base that duty on an explicit divine disposition since the beginning of the world; others, like Hinduism and Buddhism, justify it with the need to maintain cosmic harmony through a profound respect and meticulous nurturing of every element. Shared management translates into co-responsibility to be implemented with respect for the principle of subsidiarity (Baggio, 2014). Also within the secular sphere, this principle is generally accepted, to the point of becoming a foundation of the international agreements related to questions of common interest. In this sense, the preamble of the Paris Agreement on climate change is emblematic, which affirms as fundamental "the principle of equity and common but differentiated responsibilities and respective capabilities, in the light of different national circumstances" (UN, 2015a, Preamble).

A sixth principle can be deduced from the sense of transnational belonging advocated by different religious traditions. Some of these affirm the existence of a "universal citizenship" founded on the adherence to a specific faith rather than national belonging. In a transcendent perspective, every earthly country in any case is transitory compared to the real celestial land, which you reach after death. Other religions more simply consider nationality as a spatialtemporal accident in the cycle of rebirths, which reveals the cosmic belonging of each being. It should also be underlined that these religions teach respect for the existing political constructions but push believers to look beyond every historical structuring. Some philosophical traditions coincide with this vision of citizenship, underlining the precariousness of every spatial-temporal juridical determination and they insist on the concept of "global fraternity". On the 
other side, one has to admit that, if nationality can be given or taken, it cannot constitute a real source of personal identity (Baggio, 2014).

These six principles do not in any way exhaust the wealth of common heritage of global religious and philosophical traditions. However, they represent a concrete example of how an approach that is inclusive of religions in the public debate can contribute substantially to identifying and sharing essential principles and values for a convivial cohabitation, which is particularly necessary in an age that has rightly been defined by some scholars as the age of migration (Castle et al., 2014).

Even if we mentioned above the importance of the religious dimension in the phase of arrival and residence, we consider it is worthwhile to go into more depth at this point on the role that religions often play in the process of integration with a view to a mutually enriching multi-ethnic cohabitation. In 2016, D. Nagy and M. Frederiks observed that this particular argument had not been especially studied by researchers, probably based on the unfounded assumption that in the integration process religion was being progressively relegated to the private sphere, in this way becoming uninfluential in the dynamic of identity reconfiguration (Nagy, Frederiks, 2016). A more attentive bibliographical research, however, reveals that there is no lack of studies that have tackled this topic in recent years. Many of these highlight the positive contribution of religion in the process of integration, dwelling on very varied aspects (LyckBowen, Owen, 2018). As a methodological choice, we limited to analyzing the studies that refer directly to the European reality.

Firstly, religion contributes generally toward the conservation of migrants' original identity, which is necessary to start a constructive dialogue in the integration process, without easy concessions to assimilation pressures. In 2008, Annemarie Dupré underlined how in the case of Christian communities in Europe, for many migrants, religion represented an essential element for the maintenance of their ethnic or national identity and, at the same time, a source of "transnational" identity, which facilitates moving beyond the former (Dupré, 2008). In 2011, Jørn Borup and Lars Ahlin, after having studied the case of Catholic Vietnamese migrants in Denmark, observed how religion had played a crucial role in the maintenance of the identity of a minority group, even if it had not in fact encouraged a subsequent step toward integration (Borup, Ahlin, 2011). In 2012, some Spanish researchers, analyzing the migration reality in the Castile and León region, concluded that migrant communities originally 
from Morocco, Sub Saharan Africa and Latin America consider religion -and above all religious practice- an important element for their collective and individual identity redefinition (Valero Matas et al., 2012). In 2013, Claudia Diehl and Matthias Koenig noted how for two different groups of migrants in Germany, Turkish Muslims and Polish Catholics, religious practice, initially reduced upon contact with a largely secular society, was then recovered to rediscover their own identity which had been "diluted" in the initial years (Diehlm, Koenig, 2013). A recent study on the reality of Muslim migrants in Europe concludes that, despite the many prejudices and the hostility of the native population, religion can encourage significant links between minority groups and between the minority groups and the majority group; this can contribute to mitigating the stress of the process of adaptation, foster a sense of collective belonging in second generations and offer refuge from discrimination experienced in host societies (Papademetriou et al., 2016).

A second aspect highlighted by the studies consulted refers to the positive effect of religion on the willingness of migrants to collaborate in the construction of integrated communities in the countries of immigration. In her analysis, Dupré underlines two elements: on the one hand, the importance of the positive experience of inclusion of migrants in religious communities in the host societies, which often reproduces a climate of fraternity experienced in one's home country; on the other, the recognition of common religious values which, translated in ethical terms, serve to promote peaceful and convivial cohabitation (Dupré, 2008). In 2013, presenting the results of research on integration of citizens from third countries in the European Union, Jocelyne Cesari underlined how active and structured religious participation generally represents an element encouraging the political participation of migrants (Cesari, 2013). Religion can function also as a driving force for the emancipation of minority migrant groups from particularly stringent political, social and economic structures in immigration countries, like in the case of the Sri Lankan Tamil community in Britain studied by Donald Taylor (Taylor, 1991).

A final element worthy of consideration is that underlined by Majbritt LyckBowen and Mark Owen in a very recent article, which is the contribution of cooperation between religions to the process of integration. According to the authors, a multi-religious approach can be of benefit for the improvement of services supporting the integration process, and the intensification of collaboration between religious organizations and communities, with positive consequences on dynamics of inclusion, and the creation of a social fabric that is more open and respectful of differences (Lyck-Bowen, Owen, 2018).

There are many cases in which religion has been fundamental for the creation of ad hoc structures and the organization of services for migrants and 
refugees. In 2004, Charles Hirschman stated that religions play a triple role in the life of migrants, codified with the formula of the three "rs": refuge, respect and resources. And it was to obtain one of these "rs" that migrants decided generally to affiliate themselves with this or that religious group (Hirschman, 2004). This interpretation, while with all its limitations, is reflected in that which many religious organizations and communities tend to offer their faithful in the various phases of the migration process (see on this point Chapter 12).

In my missionary experience, I have had the chance to get to know numerous associations, organizations and foundations of declared religious inspiration, which have made assistance to migrants and refugees their main reason of being. In the origin countries, they dedicate themselves to providing useful information on emigration, preparing the departing and their relatives who remain in the homeland, demanding more protection of migrants on the part of accountable institutions and assisting migrants and their families in making the migration experience a real development opportunity. In the transit countries, they usually offer refugees and migrants assistance and refuge, seeking to satisfy their fundamental needs. In the destination countries, they offer a wide range of services both in the spiritual as well as in the social sphere, in many cases promoting integration between migrants and native peoples, active participation, with respect for differences, as well as the reinforcement of transnational dynamics with positive effects on development of origin communities.

Summing up the conclusions of various studies on the issue, in 2004 Alejandro Portes and Josh DeWind observed that in the US, religious institutions contributed in a significant way to the integration process of migrants through the support of a positive reception, the mitigation of any negative attitudes, collaboration with the accountable authorities toward inclusion, the protection of minority groups from exclusion, support toward the incorporation of new arrivals and equally of their transnational practices and help to migrant parents toward ensuring a positive integration of their children (Portes, DeWind, 2004) (Chapter 20).

In his 2003 article, Christian Troll noted that from the 1970s in Germany, Muslim associations in which the first aim was to guarantee places of worship to the migrant faithful had multiplied, but also noted that, over the years, they had widened their range of action, elevating themselves to official representatives of their members in the public sphere and, in this way, offering learning courses and going into more depth on the Koran. From the 1980s, many of these associations came together in federations, often with a strong national connotation, to ensure better religious assistance to members, guarantee a greater political weight to Muslim communities, initiate dialogue with 
Christianity, educate young generations in the doctrine of Islam and create and manage Islamic cultural centers (Troll, 2003).

A report published in 2016 by the Churches' Commission for Migrants in Europe and by the World Council of Churches illustrated in detail the ministry carried out by some Christian communities in Europe to the benefit of migrants and refugees, underlining as spheres of specific commitment their inclusion in the life and apostolate of local Churches, the accompaniment of young people, social assistance and the work of advocacy (Jackson, Passarelli, 2016).

\section{5}

\section{Valuing Religion and Interreligious Dialogue}

From what has been presented above, we believe we can affirm that the importance of the religious dimension in the migration experience appears evident. Since it constitutes an important aspect in the life of the great majority of migrants, it has to be considered in all its potentiality in the governance of migration and multi-ethnic cohabitation. Interreligious dialogue represents a privileged instrument to increase and release that potential, inasmuch as the participation of many actors, all authoritative and animated by common principles and values, is already a guarantee of success.

In 2014, Pope Francis affirmed that

Religious freedom (...) is a shared space (...) an atmosphere of respect and cooperation that must be built with everyone's participation, even those who have no religious convictions. (Francis, 2014)

For the construction and the maintenance of this shared space, it is essential to promote dialogue and meeting between the different religions and between them and institutions with every means.

Those meetings should be favored both at the level of religious leaders as well as at the level of the faithful, so as to harmonize theoretical exchange on principles and values with dialogue on concrete questions of day-to-day life. It is appropriate for them to be organized in neutral spaces, guaranteeing the participants the possibility of expressing themselves in utmost liberty. It is convenient also to foresee moments of informal, recreational, sportive and artistic meeting, to widen the opportunities of expression beyond the knowledge of language. Ecumenical and interreligious prayer meetings, furthermore, represent the highest expression of reciprocal recognition and respect, inasmuch as the communication takes place in the sphere of the sacred. 
Sincere dialogue and the enriching encounter between religions and between religions and institutions can prepare the ground for the development of shared initiatives and programs, characterized by a multi-religious approach. The already-cited study of M. Lyck-Bowen and M. Owen (2018) presents five concrete examples of that collaboration at the European level.

Refugee Support is a psychological and social assistance program for asylum seekers and refugees in Britain. Managed by the British Red Cross, it relies upon the cooperation of different religious, interreligious and secular organizations.

The second project, entitled Goda Grannar (good neighbors) sprang from a spontaneous collaboration between a Christian Church and a mosque in the offering of temporary lodging and food to migrants in transit at Stockholm station. In 2015, the collaboration was structured in a common program that added among its services teaching of the language, legal assistance and the directing of those assisted to the competent public offices.

With the objective of accompanying migrants in the integration process in Germany, the project Weisst Du Wer Ich bin? (Do you know who I am?) brought together Muslims, Christians and Jews of good will. This project is supported financially by the Federal Government.

Dialogue for Integration-a Multi-Faith Approach is a program promoted by the Afryka Connect Foundation to improve relations between African migrants and the local population in Poland. This program foresees a series of training seminars for leaders of different religions and representatives of institutions.

The last project studied by the two researchers is that of the "Humanitarian Corridors" through which hundreds of particularly vulnerable refugees and asylum seekers are rapidly relocated in Italy. The initiative, promoted jointly by the (Catholic) Community of Sant'Egidio and by the Waldensian Church (see Chapter 10), saw the effective informal collaboration of some Muslim communities and mosques on Italian territory.

Interreligious dialogue is a privileged vehicle for valuing the religious dimension of natives and migrants, and every political exercise aimed at the governance of migration and multi-ethnic cohabitation should consider it. Starting from my experience, I would like to highlight five concrete ways of valuing the religious dimension, without any claim of being exhaustive in my proposal.

1) The first way of valuing religion in the governance of migration is guaranteeing its freedom, both in its profession as well as in its practice. In 2017, the Migrants and Refugees Section of the Dicastery for Promoting Integral 
Human Development of the Vatican encouraged states to "adopt policies and practices that guarantee the freedom of religion, in both belief and practice, to all migrants and refugees regardless of their migratory status" (Migrants and Refugees Section, 2017, 17).

2) The reason for the encouragement is due to the observation that in some countries, by law, it is not permitted to affiliate oneself with or publicly practice a religion that is different from that of the majority of citizens. In that sense, migrants, who often make up a large percentage of religious minorities in these countries, find themselves prevented from freely expressing their faith, above all when this requires collective participation (Chapter 10).

3) It is not enough to recognize freedom of worship as an individual and collective right. It is also necessary to ensure its exercise. For this reason, States have to concede to the use of appropriate structures of worship, so that spaces and things that belong to the sacred sphere that many faithful turn to with devotion can be treated with the due respect. This concession would serve to guarantee the dignity of different cultural manifestations and contribute likewise to eliminating all forms of religious "secrecy" that usually stoke suspicions and fears among the local population.

4) Guaranteeing the exercise of the right translates also in the "political" consideration of the special times, celebrations and traditions of each religion. The faithful should be put in a condition to be able to carry out the devotional practices considered as a duty in the doctrine of the professed faith, with all those elements considered "obligatory" (rests, fasting, food etc.) with the aim of religious compliance, always and when these do not violate local laws and do not undermine the fundamental rules of peaceful and respectful cohabitation.

5) For an effective exercise of freedom of worship, the competent authorities have to eliminate or prevent every form of discrimination of a religious origin. This can be achieved through a relentless pursuit of every discriminatory attitude and specific awareness-raising campaigns that have mutual tolerance and respect as their aim. Focusing on the medium to long term results, it would be all the more opportune to introduce teaching modules in educational curricula of primary and secondary schools that allow students to get to know different religions, seeing as ignorance is frequently the source of prejudices, which in turn produce fears and conflicts.

The guarantee of the exercise of religious freedom, both in its profession and its practice, undoubtedly makes up a first step toward the valuing of religion, but it does not determine in itself any proactive commitment on the part of 
the state. The real appreciation of the value of the religious dimension is demonstrated by its inclusion in the formulation of policies and programs targeted at the departure, transit, entrance, residence and return of migrants.

In the Message for the World Day of Migrants and Refugees 2018, entitled "Welcoming, protecting, promoting and integrating migrants and refugees", Pope Francis explained how the four verbs of the title were the summary of the pastoral action of the Church for migrants and refugees. In the paragraph dedicated to "promoting", the Holy Father underlined how religion makes up an essential dimension of integral human development, the search for which represents the main cause of the large part of contemporary migration flows.

Promoting essentially means a determined effort to ensure that all migrants and refugees -as well as the communities that welcome them-are empowered to achieve their potential as human beings, in all the dimensions that constitute the humanity intended by the Creator. Among these, we must recognize the true value of the religious dimension. (Francis, 2017)

It would be interesting, as a scientific exercise, to encourage an objective assessment of the consideration of the religious dimension in migration policies and programs of the countries of departure, transit, and destination. The privileged observatory in which I find myself working today has allowed me to draft a few attempts in this direction. Rarely have I managed to find significant references to religion in the policies and programs that I have analyzed. Often, those references were motivated either by the will to prevent every form of discrimination toward minority religious groups, or by the concern about maintaining a neutral attitude toward each faith (or not to consider it in political practice) or by the need for greater control over who professes this or that religion.

The inclusion of the religious dimension in the formulation of migration policies and programs of the departure countries means the acknowledgment of the role of religions in the discernment process leading to the decision to migrate and to the immediate preparation for the departure. It also means the recognition of situations where the impossibility of confessing and practicing a specific religion is the cause of a forced migration. Such situations highlight the need for promoting appropriate measures toward resolving this problem.

Migration policies and programs in transit countries cannot ignore the influence of the religiosity of migrants on their capacity of resilience and on the conservation of hope beyond any logical reasoning. Considering the religious dimension, "politically" means ensuring places of worship and prayer to all 
itinerant people and encouraging their referral, when possible, to local ministers of the same religion.

With regard to the destination countries, the religious dimension has to be included in initial reception policies and programs, in those of integration in the medium to long term and those of returning. Above, we have already highlighted the positive potential of religion in this migration phase - potential that has to be opportunely released through appropriate and far-sighted normative and institutional interventions. We would like to underline the transnational significance of the religious dimension of migrant communities, which requires special attention and a considered appreciation when elaborating bilateral or multilateral agreements on migration questions.

The inclusion of the religious dimension in the formulation of migration policies and programs also regards the international community, which for some years has inserted migration among the main issues of its common agenda. Unfortunately, it seems that this has not yet happened. In the document of the United Nations entitled "Transforming our World: the 2030 Agenda for Sustainable Development", we find just two very short mentions of religion to say that this cannot ever be an element of discrimination (UN, 2015b: 19). The same applies for the New York Declaration for Refugees and Migrants from 2016 (UN, 2016: 13-14). Neither the word "religion" nor the word "faith" ever appear in the text of the report by the United Nations Secretary General entitled Making migration work for all and published at the end of 2017 (UN Secretary General, 2017). The final drafts of the "Global Compact on Refugees" (UN, 2018a: 9) and the "Global Compact for Safe, Orderly and Regular Migration" (UN, 2018b: 31a) are situated on the same line as the "New York Declaration".

All of the studies analyzed highlight the fundamental role that religious organizations are playing in the maintenance of "faith" among migrants and refugees, offering cultural services and guaranteeing appropriate spaces and spiritual counselling. They are often committed to the maintenance of original identity, promoting the richness of different cultures. Many have widened the range of services offered, responding to the most varied needs of their faithful. Even with different ways and with different motivations, the large part of them has in any case contributed positively to the process of integration of migrants and refugees in the host communities.

The enormous role played by religious organizations in favor of migrants and refugees has to be appropriately recognized and appreciated on the part of institutions. That appreciation has to translate in terms of legislative, political and financial support. In the first place, it is essential that national and/or local legislation consider and order their legal existence through clear regulation and simple procedures for inclusion in public registers. Religious organizations, 
then, have to be appropriately considered in the formulation of policies on emigration, entrance, integration and return, with a view to the activation of useful synergies toward a better governance of the migration phenomenon and the construction of intercultural and plural societies. Institutions, finally, have to insert the financing of those synergies in their public spending estimate, guaranteeing religious organizations the possibility of participating actively in activities and programs in favor of migrants and refugees, as well as cover for expenses generated by that participation. The authorities in charge have to equip themselves with mechanisms of monitoring and checking of the work of religious organizations with the aim of guaranteeing maximum transparency.

Between 2008 and 2010, I directed research into the relationship between Philippine migrant associations and Philippine institutions, entitled Migrant Associations and Philippine Institutions for Development (MAPID). The large part of the migrants interviewed said they had lost their faith in homeland institutions, considered "to blame" in some way for their emigration (Baggio, 2010). On the other hand, the same migrants showed they placed much faith in the Catholic Church and in other religious organizations (Asis, Roma, 2010; Villarroya Soler, 2010; Zanfrini, Sarli, 2010). I had the opportunity to personally note similar situations related to other groups of migrants and in other geographical contexts. With regard to refugees, the loss of faith in authorities of their own country made up one of the main reasons of their forced migration. In many cases, the mistrust is not limited to countries of origin, but extends as a consequence also to those of the countries of immigration. Collaboration between institutions and religious organizations can favor the re-establishment of a relationship of trust between migrants and public authorities, generating fertile ground for an open and constructive dialogue. The opportunity to institutionalize that collaboration therefore appears evident, inviting representatives of the different religious organizations to participate in the committees and round tables on migration questions and integration processes.

Considering the presence of a considerable number of highly diversified stakeholders, it is appropriate for States to promote an inclusive and effective cooperation between the different religious organizations. It would be useful to entrust the institutions that are responsible with the task of coordinating the actions of religious organizations in favor of migrants and refugees, always with respect for the relative prerogatives and autonomies.

The importance of collaboration with religious organizations is clearly affirmed in the final draft of the "Global Compact for Safe, Orderly and Regular Migration": "We will implement the Global Compact in cooperation and partnership with migrants, civil society, migrant and diaspora organizations, 
faith-based organizations, local authorities and communities, the private sector, trade unions, parliamentarians" (UN, 2018b: 44). The final text of the "Global Compact on Refugees", after having included religious organizations among the "relevant stakeholders" in the division of responsibility for aid, at point 41 affirms that: "Faith-based actors could support the planning and delivery of arrangements to assist refugees and host communities, including in the areas of conflict prevention, reconciliation, and peace-building, as well as other relevant areas" (UN, 2018a: 41).

The same text also underlines the commitment of States to make the most of the potential of civil society, religious organizations and communications means "in fostering respect and understanding, as well as combating discrimination" (UN, 2018a: 84). Echoing that emphasis is the final draft of the "Global Compact for Safe, Orderly and Regular Migration", which indicates among the commitments foreseen by the agreement to:

Engage migrants, political, religious and community leaders, as well as educators and service providers to detect and prevent incidences of intolerance, racism, xenophobia, and other forms of discrimination against migrants and Diasporas and support activities in local communities to promote mutual respect, including in the context of electoral campaigns. (UN, 2018b: 33)

For this reason, it is important that institutions make efforts to offer religious leaders and directors of religious organizations accessible training opportunities, aimed at the acquisition of the necessary skills for far-sighted guidance, conscientious teaching and a significant functioning in the migration sphere. Every investment in this sense will be generously repaid by results in the field. These offers of training, when they are capable of attracting representatives from different religious groups, could also ensure spaces of shared planning and favor the creation of operational networks.

The multiple services offered by religious organizations beyond the purely spiritual area are often entrusted to volunteers, whose generosity is not always matched by adequate training. To bridge this gap, institutions could create courses of certification and professionalization of skills for workers of religious organizations. These courses could also provide the same workers greater information on existing regulation around the services offered and on the possibilities and/or opportunities to redirect cases.

The inadequate consideration of the religious dimension in the provision of services on the part of institutions can produce serious problems, such as the formulation of judgements tainted by ignorance of the limits imposed by 
religious traditions, discrimination in access to services and the generation of hostile sentiment in some minorities. For this reason, it is appropriate for public officials to be educated on the essential elements of different religions, in particular on beliefs and religious practices that can have a strong impact on the social life of the faithful. 